\title{
Gas Chromatographic Determination of Thiocyanate Ion in Biological Fluids Using Immobilized Phase-Transfer Catalyst for Derivatization
}

\author{
Takeji Chikamoto and Takeshi MaItani \\ Kyoto Prefectural Institute of Hygienic and Environmental Sciences, Murakami, Fushimi, Kyoto 612
}

\begin{abstract}
A new gas chromatographic method was developed for the determination of thiocyanate ion in biological fluids. Fluid sample solutions deproteinized with acetone or methanol were centrifuged. After evaporation of the organic solvent of the supernatant by a rotary evaporator, thiocyanate ion was ethylated with ethyl iodide in an immiscible aqueous phase-organic phase system by using an immobilized phase-transfer catalyst. The resulting ethyl thiocyanate was determined by gas chromatography on a $20 \%$ polyethylene glycol $20 \mathrm{M}$ column. Either a flame ionization detector (FID) or a flame thermionic detector (FTD) was used. The method was capable of determining thiocyanate ion concentrations in the range of 5 to $40 \mu \mathrm{g} / \mathrm{ml}$ with the FID and 0.05 to $20 \mu \mathrm{g} / \mathrm{ml}$ with the FTD. The detection limits were $1 \mu \mathrm{g} / \mathrm{ml}$ with the FID and $0.01 \mu \mathrm{g} / \mathrm{ml}$ with the FTD. The recoveries of thiocyanate ion added to cow's milk, human saliva, and human urine samples were over $92 \%$ with good repeatability.
\end{abstract}

Keywords Determination of thiocyanate ion, biological fluid, immobilized phase-transfer catalyst, gas chromatography, flame ionization detector, flame thermionic detector

Small amounts of thiocyanate ion are present in mammalian tissues as a normal constituent, and the antithyroid effect of this ion through the inhibition of iodine uptake in the thyroid gland is well known. ${ }^{1-3}$ The level of thiocyanate ion as a metabolite of cyanide ion in human body fluids (e.g., plasma) has been used as a biochemical measure of dietary ingestion of cyanide and/or exposure to cyanide.

Recently, attempts have been made to determine trace amounts of thiocyanate ion in biological materials by gas chromatographic methods with derivatization $^{3-5}$, because many current spectrophotometric methods are not sensitive enough. ${ }^{3}$ Several other methods employing the derivatization of thiocyanate ion have been reported for the gas chromatographic determination. ${ }^{6-9}$

In the present study, we have developed a new, simple, and sensitive method for the determination of thiocyanate ion by gas chromatography (GC). In this method, the derivatization of thiocyanate ion to ethyl thiocyanate using a cryptand immobilized on a polymer matrix as a catalyst was followed by the gas chromatographic determination with either a flame ionization detector (FID) or a flame thermionic detector (FTD). The proposed method is applied to the determination of thiocyanate ion concentrations in cow's milk, human saliva, and human urine.

\section{Experimental}

\section{Reagents}

All chemicals used were of analytical-reagent grade. Deionized and distilled water was used throughout.

A standard stock solution of thiocyanate ion (1000 $\mu \mathrm{g} / \mathrm{ml}$ ) was prepared by dissolving $1.673 \mathrm{~g}$ of potassium thiocyanate in water and diluting to 1000 $\mathrm{ml}$. Standard solutions were prepared by dilution of the stock solution with water to give concentrations in the range of $0.01-40 \mu \mathrm{g} / \mathrm{ml}$.

Kryptofix 222B polymer (100-300 $\mu \mathrm{m}$, Merrifield resin-bound cryptand [2.2.2B]), an immobilized phasetransfer catalyst, was obtained from E. Merck.

\section{Apparatus and conditions for $G C$}

A 5-ml reaction vessel with a ground-glass stopper was used for the derivatization.

The rotary evaporator used was a Sibata Model RE $120 \mathrm{~B}$.

Two gas chromatographs, equipped either with the FID or with the FTD, were used. Gas chromatographic conditions of each apparatus were as follows.

FID gas chromatograph: A Shimadzu GC-6AM gas chromatograph equipped with the FID was used. A $2.5 \mathrm{~m} \times 3 \mathrm{~mm}$ i.d. glass column packed with $20 \%$ polyethylene glycol (PEG) $20 \mathrm{M} /$ Chromosorb W (AWDMCS, 80-100 mesh) was used with nitrogen carrier gas at a flow rate of $45 \mathrm{ml} / \mathrm{min}$. Injector, column, and 
detector temperatures were 200,115 , and $200^{\circ} \mathrm{C}$, respectively.

FTD gas chromatograph: A Shimadzu GC-7A gas chromatograph equipped with an FTD (Shimadzu Model-8: hydrogen flow, $3.5 \mathrm{ml} / \mathrm{min}$; air flow, 150 $\mathrm{ml} / \mathrm{min}$ ) was used. A $2.1 \mathrm{~m} \times 2.6 \mathrm{~mm}$ i.d. glass column packed with the same packings as described above was used with helium carrier gas at a flow rate of $\mathbf{3 0}$ $\mathrm{ml} / \mathrm{min}$. Injector, column, and detector temperatures were 200,105 , and $200^{\circ} \mathrm{C}$, respectively.

\section{Preparation of sample solution}

Cow's milk. A cow's milk sample (4 g) was mixed with $6 \mathrm{ml}$ of acetone in a 10- $\mathrm{ml}$ graduated test tube. The mixture was heated at $50^{\circ} \mathrm{C}$ for $5 \mathrm{~min}$, then cooled to room temperature, and the volume was adjusted to $10 \mathrm{ml}$ with acetone. The mixture was shaken for $1 \mathrm{~min}$. After centrifugation for $10 \mathrm{~min}$ at 3000 r.p.m., $2.5 \mathrm{ml}$ of the supernatant, equivalent to $1 \mathrm{~g}$ of the milk, was transferred to a $10-\mathrm{ml}$ pear-shaped flask and evaporated to about $0.2 \mathrm{ml}$ under reduced pressure at $50^{\circ} \mathrm{C}$. The residue was transferred into the reaction vessel with the aid of a suitable amount of water, and the volume was made up to $1 \mathrm{ml}$ with water. The solution was submitted to the derivatization procedure described below. Methanol was also used as a deproteinization agent.

Human saliva. A human saliva sample $(1 \mathrm{~g})$ was mixed with $3 \mathrm{ml}$ of acetone in a 4-ml graduated test tube. The mixture was heated at $50^{\circ} \mathrm{C}$ for $5 \mathrm{~min}$, then cooled to room temperature, and the volume was adjusted to $4 \mathrm{ml}$ with acetone. The mixture was shaken for $1 \mathrm{~min}$. After centrifugation for $10 \mathrm{~min}$ at 3000 r.p.m., $2 \mathrm{ml}$ of the supernatant, equivalent to $0.5 \mathrm{~g}$ of the saliva, was treated in the same manner as for the milk sample.

Human urine. A human urine sample was diluted 3-fold with water and was directly submitted to the derivatization procedure.

\section{Derivatization procedure}

To a sample solution $(1 \mathrm{ml}), 0.2 \mathrm{ml}$ of $0.2 \mathrm{M}$ potassium hydroxide solution, $1 \mathrm{ml}$ of dichloromethane or benzene, $50 \mu \mathrm{l}$ of ethyl iodide and a spatula-tip amount (about $10 \mathrm{mg}$ ) of the catalyst were added; then the mixture was shaken at $30^{\circ} \mathrm{C}$ for $2 \mathrm{~h}$. The reaction mixture was centrifuged at 3000 r.p.m. for $5 \mathrm{~min}$, if necessary. Then the organic layer was transferred into a 2-ml test tube.

A 1-ml aliquot of each standard solution was submitted to the derivatization in the same manner.

\section{$G C$}

A 2- $\mu$ l aliquot of the organic layer obtained above was subjected to GC; the ethyl thiocyanate concentration was determined. When dichloromethane was used as the solvent on the derivatization step, the FID was employed. In the case of benzene, the FTD was employed.

\section{Results and Discussion}

\section{GC of the derivative}

The reaction product was identified as ethyl thiocyanate by comparing the retention time with that of authentic ethyl thiocyanate on the PEG 20M column and on others, such as Diasolid ZF and Porapak Q columns. A sharp and symmetrical peak of the derivative was observed on the PEG 20M column. Formation of ethyl isothiocyanate was not observed under the derivatization condition.

The derivative was stable for at least $48 \mathrm{~h}$ at room temperature after separating the organic layer, but was relatively unstable when the organic layer was left in the reaction vessel together with the aqueous layer and the catalyst.

\section{Optimization of derivatization conditions}

The present method involves ethylation of thiocyanate ion with ethyl iodide using a catalyst and subsequent GC to determine the derivative. Kryptofix 222B polymer, a polymer bearing cryptand [2.2.2B] as an anchor group, was selected as a phase-transfer catalyst. The catalyst and each one of a pair of reactants, i.e., thiocyanate ion and ethyl iodide, are located in separate phases, and the derivative formed is extracted into the organic phase by extractive ethylation. The organic layer can be injected directly into the gas chromatograph without contamination by the catalyst or by water-soluble substances.

To obtain the optimal conditions for the derivatization, we examined the effects of various factors, i.e., organic solvent and amounts of the catalyst, potassium hydroxide, and ethylating reagent, on the time course of the derivative formation by using standard solutions of thiocyanate ion at 5 and $10 \mu \mathrm{g} / \mathrm{ml}$.

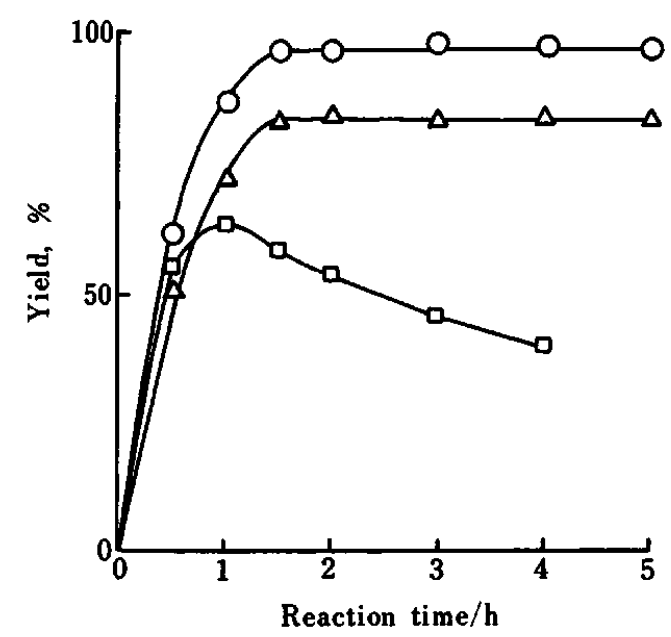

Fig. 1 Variation of the yield in the time course of derivatization at $30^{\circ} \mathrm{C}$ with different organic solvents $\left(\mathrm{SCN}^{-}, 10 \mu \mathrm{g} / \mathrm{ml}\right)$. Solvents: $O$, dichloromethane; $\triangle$, benzene; $\square$, hexane. 
Effect of organic solvent and reaction time. The choice of organic solvent affected the derivative formation, as shown in Fig. 1. Here, the yield in Fig. 1 is the product of derivatization yield and extractability. Dichloromethane could be successfully used as the organic phase, and satisfactory results were also obtained using benzene. The yields of ethyl thiocyanate reached a plateau in $1.5 \mathrm{~h}$ at $30^{\circ} \mathrm{C}$ in the case of using dichloromethane or benzene; the plateau values were $96 \%$ with dichloromethane and $83 \%$ with benzene. Therefore, the reaction time was fixed at $2 \mathrm{~h}$. The yields decreased gradually with reaction time after reaching a maximum value when hexane was used. Thus, dichloromethane or benzene was used when the FID or the FTD was employed as the detector on GC, respectively, since the use of organo-chlorine solvent is known to be unfavorable for the FTD.

Effects of amount of the catalyst and concentration of potassium hydroxide solution. Thiocyanate ion could not be converted into the ethyl derivative over at least 4 $h$ in the absence of the catalyst, Kryptofix 222B polymer. The catalyst promoted the reaction of thiocyanate ion effectively to give ethyl thiocyanate in high yields. The derivative formation proceeded in the range of 2 to $20 \mathrm{mg}$ of the catalyst in almost the same manner as in Fig. 1. The concentration of potassium hydroxide solution $(0.2 \mathrm{ml})$ added to the sample solution in the range of 0.02 to $0.5 \mathrm{M}$ gave almost the same time course of the derivatization as in Fig. 1. Quite similar results were obtained when $0.2 \mathrm{M}$ sodium hydroxide solution or $0.1 \mathrm{M}$ potassium carbonate solution was used. The yield was somewhat low when addition of the potassium hydroxide solutions was omitted. The yield decreased gradually with reaction time after reaching a maximum value in 1 to $1.5 \mathrm{~h}$ in the case of addition of 1 to $4 \mathrm{M}$ potassium hydroxide solution. Therefore, the amount of the catalyst and the concentration of potassium hydroxide solution were fixed at $10 \mathrm{mg}$ and $0.2 \mathrm{M}$, respectively.

Effect of ethylating reagent. Reaction of thiocyanate ion with ethyl bromide was somewhat slower than that with ethyl iodide. The yield reached a plateau in $1.5 \mathrm{~h}$ at $30^{\circ} \mathrm{C}$ when ethyl iodide was added in the range of 50 to $100 \mu \mathrm{l}$. The amount of ethyl iodide was fixed at 50 $\mu \mathrm{l}$, since a large amount of halides was thought to be unfavorable for the FTD.

\section{Calibration curve}

A calibration curve was constructed by plotting the peak height of the derivative versus the concentration of thiocyanate ion.

A good linear calibration curve passing through the origin at a level ranging from 5 to $40 \mu \mathrm{g} / \mathrm{ml}$ was obtained with the FID. The detection limit was 1 $\mu \mathrm{g} / \mathrm{ml}$. The relative standard deviations for five runs were $3.9 \%$ at $10 \mu \mathrm{g} / \mathrm{ml}$ and $1.7 \%$ at $20 \mu \mathrm{g} / \mathrm{ml}$.

A good linear relationship passing through the origin was also obtained in the range of 0.05 to $20 \mu \mathrm{g} / \mathrm{ml}$ with the FTD. This detector could detect thiocyanate ion at

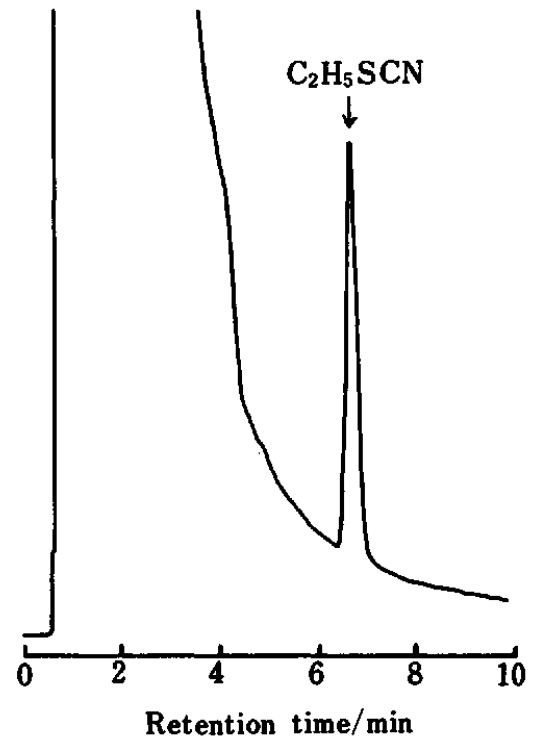

Fig. 2 Gas chromatogram (FID) obtained in the analysis of a human saliva sample ( $\mathrm{SCN}^{-}$found, $58.2 \mu \mathrm{g} / \mathrm{g}$ ).

Table 1 Determination of thiocyanate in human saliva, cow's milk and human urine with recovery test (triplicate analyses)

\begin{tabular}{|c|c|c|c|c|c|}
\hline \multicolumn{2}{|c|}{ Sample } & \multirow{2}{*}{$\begin{array}{c}\begin{array}{c}\mathrm{SCN}^{-} \\
\text {added/ } \\
\mu \mathrm{g} \mathrm{g}^{-1}\end{array} \\
0.0\end{array}$} & \multirow{2}{*}{$\begin{array}{c}\begin{array}{c}\mathrm{SCN}^{-} \\
\text {found/ } \\
\mu \mathrm{g} \mathrm{g}^{-1}\end{array} \\
43.0\end{array}$} & \multirow{2}{*}{$\begin{array}{c}\mathrm{RSD}^{\mathrm{a}} \\
\% \\
2.0\end{array}$} & \multirow{2}{*}{$\begin{array}{c}\text { Recovery } \\
\% \\
\end{array}$} \\
\hline Saliva $^{b}$ & 1 & & & & \\
\hline & & 10.0 & 53.1 & 0.3 & 101 \\
\hline & & 20.0 & 62.4 & 1.3 & 97 \\
\hline & 2 & 0.0 & 58.2 & 2.4 & \\
\hline & & 20.0 & 78.8 & 1.9 & 103 \\
\hline & & 40.0 & 97.4 & 2.1 & 98 \\
\hline \multirow[t]{5}{*}{ Milk $^{c}$} & 1 & 0.0 & 4.0 & 1.7 & \\
\hline & & 1.0 & 5.2 & 2.2 & 120 \\
\hline & 2 & 0.0 & 4.0 & 3.7 & \\
\hline & & 5.0 & 9.2 & 2.8 & 104 \\
\hline & & 10.0 & 14.2 & 3.2 & 102 \\
\hline \multirow[t]{9}{*}{ Urine $^{c}$} & 1 & 0.00 & 0.56 & 5.2 & \\
\hline & & 5.00 & 5.70 & 1.9 & 103 \\
\hline & & 10.0 & 10.5 & 2.1 & 99 \\
\hline & 2 & 0.00 & 0.80 & 8.5 & \\
\hline & & 5.00 & 5.60 & 2.6 & 96 \\
\hline & & 10.0 & 10.6 & 2.3 & 98 \\
\hline & 3 & 0.00 & 0.73 & 4.9 & \\
\hline & & 5.00 & 5.33 & 1.7 & 92 \\
\hline & & 10.0 & 10.2 & 1.7 & 95 \\
\hline
\end{tabular}

a. Relative standard deviation.

b. Determined by FID-GC.

c. Determined by FTD-GC. 
(A)

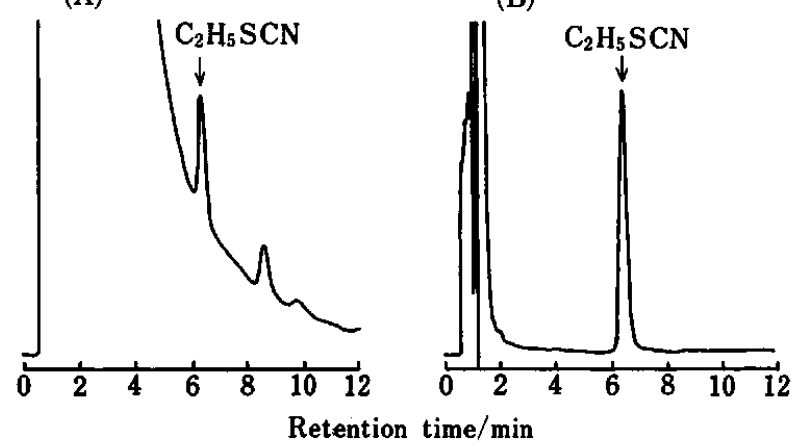

Fig. 3 Gas chromatograms obtained in the analyses of a cow's milk sample with (A) FID and (B) FTD (SCNfound, $4.0 \mu \mathrm{g} / \mathrm{g}$ ).

as low as $0.01 \mu \mathrm{g} / \mathrm{ml}$ at a signal-to-noise ratio above 3 . The relative standard deviations for five runs were $3.4 \%$ at $1 \mu \mathrm{g} / \mathrm{ml}$ and $2.5 \%$ at $5 \mu \mathrm{g} / \mathrm{ml}$.

\section{Applications}

The proposed method was applied to the determination of thiocyanate ion in biological fluids, i.e., human saliva, cow's milk, and human urine. Deproteinization with acetone or methanol gave almost clear sample solutions. The deproteinization process was unnecessary for the urine samples. It was necessary to dilute the urine samples with water in order to avoid marked emulsification during the derivatization process.

The recovery tests for thiocyanate ion added to these samples were carried out in order to assess the efficiency of the proposed method. The analytical results with recovery tests are shown in Table 1. The human saliva and human urine samples were obtained from a nonsmoking man. The recoveries of thiocyanate ion were all over $92 \%$, and the relative standard deviations of the determined values were less than $9 \%$. The gas chromatogram obtained in the analysis of a saliva sample is given in Fig. 2. This shows that the thiocyanate ion level in saliva can be readily detected by using the FID. The gas chromatograms obtained in the analyses of a cow's milk sample with the FID and FTD are given in Fig. 3. The peak of retention time, $8.5 \mathrm{~min}$ in Fig. 3(A), originates from impurities in the acetone used as the deproteinization agent. As shown in Fig. 3, thiocyanate ion at trace levels can be detected sensitively with the FTD. The results mentioned above indicate that there is no interference from the sample matrices in the derivatization step or in the gas chromatographic determination.

A gas chromatographic method has been developed for the determination of thiocyanate ion at trace levels. The method was simple and sensitive. The practical advantages of carrying out the heterogeneous reaction for the derivatization using the immobilized catalyst are the readiness of the extraction of the derivative into the organic layer and the separation of the organic layer from the catalyst and the aqueous layer. The present method was applicable to the determination of thiocyanate ion in biological fluids such as human saliva, cow's milk, and human urine.

We thank Professor Toyokichi Kitagawa, Faculty of Science, Osaka City University, and Emeritus Professor Motonori Fujiwara, Kyoto University, for their helpful discussions and encouragements.

Presented at the 48th Meeting of The Food Hygienic Society of Japan, Fukui, October 1984.

\section{References}

1. A. I. Virtanen, "Final Report on Investigations on the Alleged Goitrogenic Properties of Milk", Biochemical Institute, Helsinki (1963).

2. R. D. Montgomery, "Toxic Constituents of Plant Foodstuffs", Edited by I. E. Liener, Academic Press, New York and London (1969).

3. H. F. de Brabander and R. Verbeke, J. Chromatogr., 138, 131 (1977).

4. I. Thomson and R. A. Anderson, J. Chromatogr., 188, 357 (1980).

5. K. Funazo, M. Tanaka and T. Shono, Anal. Chem., 53, 1377 (1981).

6. M. Tanaka, K. Funazo, T. Hirashima and T. Shono, J. Chromatogr., 234, 373 (1982).

7. W. Faigle and D. Klockow, Fresenius' Z. Anal. Chem., 310, 33 (1982).

8. H. -L. Wu, S. -H. Chen, S. -J. Lin, W. -R. Hwang, K. Funazo, M. Tanaka and T. Shono, J. Chromatogr., 269, 183 (1983).

9. K. Funazo, H. -L. Wu, K. Morita, M. Tanaka and T. Shono, J. Chromatogr., 319, 143 (1985).

(Received December 16, 1985)

(Accepted January 28, 1986) 